\title{
On Volatility Swaps for Stock Market Forecast: Application Example CAC 40 French Index
}

\author{
Halim Zeghdoudi, ${ }^{1,2}$ Abdellah Lallouche, ${ }^{3}$ and Mohamed Riad Remita ${ }^{1}$ \\ ${ }^{1}$ LaPS Laboratory, Badji-Mokhtar University, BP 12, 23000 Annaba, Algeria \\ ${ }^{2}$ Department of Computing Mathematics and Physics, Waterford Institute of Technology, Waterford, Ireland \\ ${ }^{3}$ Université 20 Aout, 1955 Skikda, Algeria
}

Correspondence should be addressed to Halim Zeghdoudi; hzeghdoudi@yahoo.fr

Received 3 August 2014; Revised 21 September 2014; Accepted 29 September 2014; Published 9 November 2014

Academic Editor: Chin-Shang Li

Copyright (C) 2014 Halim Zeghdoudi et al. This is an open access article distributed under the Creative Commons Attribution License, which permits unrestricted use, distribution, and reproduction in any medium, provided the original work is properly cited.

This paper focuses on the pricing of variance and volatility swaps under Heston model (1993). To this end, we apply this model to the empirical financial data: CAC 40 French Index. More precisely, we make an application example for stock market forecast: CAC 40 French Index to price swap on the volatility using $\mathrm{GARCH}(1,1)$ model.

\section{Introduction}

Black and Scholes' model [1] is one of the most significant models discovered in finance in XXe century for valuing liquid European style vanilla option. Black-Scholes model assumes that the volatility is constant but this assumption is not always true. This model is not good for derivatives prices founded in finance and businesses market (see [2]).

"The volatility of asset prices is an indispensable input in both pricing options and in risk management. Through the introduction of volatility derivatives, volatility is now, in effect, a tradable market instrument" Broadie and Jain [3].

Volatility is one of the principal parameters employed to describe and measure the fluctuations of asset prices. It plays a crucial role in the modern financial analysis concerning risk management, option valuation, and asset allocation. There are different types of volatilities: implied volatility, local volatility, and stochastic volatility (see Baili [4]).

To this end, the new financial products are variance and volatility swaps, which play a decisive role in volatility hedging and speculation. Investment banks, currencies, stock indexes, finance, and businesses markets are useful for variance and volatility swaps.

Volatility swaps allow investors to trade and to control the volatility of an asset directly. Moreover, they would trade a price index. The underlying is usually a foreign exchange rate (very liquid market) but could be as well a single name equity or index. However, the variance swap is reliable in the index market because it can be replicated with a linear combination of options and a dynamic position in futures. Also, volatility swaps are not used only in finance and businesses but in energy markets and industry too.

The variance swap contract contains two legs: fixed leg (variance strike) and floating leg (realized variance). There are several works which studied the variance swap portfolio theory and optimal portfolio of variance swaps based on a variance Gamma correlated (VGC) model (see Cao and Guo [5]).

The goal of this paper is the valuation and hedging of volatility swaps within the frame of a $\operatorname{GARCH}(1,1)$ stochastic volatility model under Heston model [6]. The Heston asset process has a variance that follows a Cox et al. [7] process. Also, we make an application by using CAC 40 French Index.

The structure of the paper is as follows. Section 2 considers representing the volatility swap and the variance swap. Section 3 describes the volatility swaps for Heston model, gives explicit expression of $\sigma_{t}^{2}$, and discusses the relationship between GARCH and volatility swaps. Finally, we make an application example for stock market forecast: CAC 40 French Index using GARCH/ARCH models. 


\section{Volatility Swaps}

In this section we give some definitions and notations of swap, stock's volatility, stock's volatility swap, and variance swap.

Definition 1. Swaps were introduced in the 1980s and there is an agreement between two parties to exchange cash flows at one or several future dates as defined by Bruce [8]. In this contract one party agrees to pay a fixed amount to a counterpart which in turn honors the agreement by paying a floating amount, which depends on the level of some specific underlying. By entering a swap, a market participant can therefore exchange the exposure from the varying underlying by paying a fixed amount at certain future time points.

Definition 2. A stock's volatility is the simplest measure of its risk less or uncertainty. Formally, the volatility $\sigma_{R}(S)$ is the annualized standard deviation of the stock's returns during the period of interest, where the subscript $R$ denotes the observed or "realized" volatility for the stock $S$.

Definition 3 (see [9]). A stock volatility swap is a forward contract on the annualized volatility. Its payoff at expiration is equal to

$$
N\left(\sigma_{R}(S)-K_{\mathrm{vol}}\right)
$$

where $\sigma_{R}(S):=\sqrt{(1 / T) \int_{0}^{T} \sigma_{s}^{2} d s}, \sigma_{t}$ is a stochastic stock volatility, $K_{\mathrm{vol}}$ is the annualized volatility delivery price, and $N$ is the notional amount of the swap in Euro annualized volatility point.

Definition 4 (see [9]). A variance swap is a forward contract on annualized variance, the square of the realized volatility. Its payoff at expiration is equal to

$$
N\left(\sigma_{R}^{2}(S)-K_{\text {var }}\right)
$$

where $K_{\mathrm{var}}$ is the delivery price for variance and $N$ is the notional amount of the swap in Euros per annualized volatility point squared.

Notation 1. We note that $\sigma_{R}^{2}(S)=V$.

Using the Brockhaus and Long [10] and Javaheri [11] approximation which is used in the second order Taylor formula for $\sqrt{x}$, we have

$$
E(\sqrt{V}) \approx \sqrt{E(V)}-\frac{\operatorname{Var}(V)}{8 E^{3 / 2}(V)},
$$

where $\operatorname{Var}(V) / 8 E^{3 / 2}(V)$ is the convexity adjustment. Thus, to calculate volatility swaps we need both $E(V)$ and $\operatorname{Var}(V)$.

The realized discrete sampled variance is defined as follows:

$$
V_{n}(S):=\frac{n}{(n-1) T} \sum_{i=1}^{n} \ln ^{2}\left(\frac{S_{t_{i}}}{S_{t_{i-1}}}\right), \quad V:=\lim _{n \rightarrow \infty} V_{n}(S),
$$

where $T$ is the maturity (years or days).

\section{Volatility Swaps for Heston Model}

3.1. Stochastic Volatility Model. Let $\left(\Omega, F, F_{t}, \mathbb{P}\right)$ be probability space with filtration $F_{t}, t \in[0 ; T]$. We consider the riskneutral Heston stochastic volatility model for the price $S_{t}$ and variance follows the following model:

$$
\begin{aligned}
& d S_{t}=r_{t} S_{t} d t+\sigma_{t} S_{t} d w_{1}(t), \\
& d \sigma_{t}^{2}=k\left(\theta^{2}-\sigma_{t}^{2}\right) d t+\xi \sigma_{t} d w_{2}(t),
\end{aligned}
$$

where $r_{t}$ is deterministic interest rate, $\sigma_{0}>0$ and $\theta>0$ are short and long volatility, $k>0$ is a reversion speed, $\xi>0$ is a volatility of volatility parameter, and $w_{1}(t)$ and $w_{2}(t)$ are independent standard Brownian motions.

We can rewrite the system ( $S 1)$ as follows:

$$
\begin{aligned}
d S_{t} & =r_{t} S_{t} d t+\sigma_{t} S_{t} d w_{1}(t) \\
d \sigma_{t}^{2}= & k\left(\theta^{2}-\sigma_{t}^{2}\right) d t+\rho \xi \sigma_{t} d w_{1}(t) \\
& +\xi \sqrt{1-\rho} \sigma_{t} d w(t),
\end{aligned}
$$

where $w(t)$ is standard Brownian motion which is independent of $w_{1}(t)$ and the indicator economic $X$. Let $\operatorname{cov}\left(d w_{1}(t), d w_{2}(t)\right)=\rho d t$, and we can transform the system $(S 2)$ to $(S 1)$ if we replace $\rho d w_{1}(t)+\sqrt{1-\rho} d w(t)$ by $d w_{2}(t)$.

3.2. Explicit Expression and Properties of $\sigma_{t}^{2}$. In this section we reformulated the results obtained in [12], which are needed for study of variance and volatility swaps, and price of pseudovariance, pseudovolatility, and the problems proposed by He and Wang [13] for financial markets with deterministic volatility as a function of time. This approach was first applied to the study of stochastic stability of Cox-Ingersoll-Ross process in Swishchuk and Kalemanova [14]. The Heston asset process has a variance $\sigma_{t}^{2}$ that follows Cox et al. [7] process, described by the second equation in $(S 1)$. If the volatility $\sigma_{t}$ follows Ornstein-Uhlenbeck process (see, e.g., Oksendal $[15])$, then Ito's lemma shows that the variance $\sigma_{t}^{2}$ follows the process described exactly by the second equation in (S1).

We start to define the following process and function:

$$
\begin{gathered}
v_{t}:=e^{k t}\left(\sigma_{t}^{2}-\theta^{2}\right), \\
\Phi(t):=\xi^{-2} \int_{0}^{t} e^{k \Phi(s)}\left(\sigma_{0}^{2}-\theta^{2}+\widetilde{w}_{2}(s)+\theta^{2} e^{2 k \Phi(s)}\right)^{-1} d s .
\end{gathered}
$$

Definition 5. We define $B(t):=\widetilde{w}_{2}\left(\Phi_{t}^{-1}\right)$, where $\widetilde{w}_{2}$ is an $\mathscr{F}_{t^{-}}$ measurable one-dimensional Wiener process, $\widetilde{\mathscr{F}}_{t}:=\mathscr{F}_{\Phi_{t}^{-1}}$, and $t \wedge s:=\min (t, s)$, where $\Phi_{t}^{-1}$ is an inverse function of $\Phi_{t}$. The properties of $B(t)$ are as follows:

(a) $\widetilde{\mathscr{F}}_{t}$-martingale and $E(B(t))=0$;

(b) $E\left(B^{2}(t)\right)=\xi^{2}\left(\left(\left(e^{k t}-1\right) / k\right)\left(\sigma_{0}^{2}-\theta^{2}\right)+\left(\left(e^{2 k t}-1\right) / 2 k\right) \theta^{2}\right)$;

(c) $E(B(s) B(t))=\xi^{2}\left(\left(\left(e^{k(t \wedge s)}-1\right) / k\right)\left(\sigma_{0}^{2}-\theta^{2}\right)+\left(\left(e^{2 k(t \wedge s)}-\right.\right.\right.$ 1) $\left./ 2 k) \theta^{2}\right)$. 


\section{Lemma 6.}

(a) Consider the following:

$$
\sigma_{t}^{2}=e^{-k t}\left(\sigma_{0}^{2}-\theta^{2}+B(t)\right)+\theta^{2},
$$

(b)

$$
E\left(\sigma_{t}^{2}\right)=e^{-k t}\left(\sigma_{0}^{2}-\theta^{2}\right)+\theta^{2}
$$

(c)

$$
\begin{aligned}
E\left(\sigma_{s}^{2} \sigma_{t}^{2}\right)= & \xi^{2} e^{-k(t+s)}\left(\frac{e^{k(t \wedge s)}-1}{k}\left(\sigma_{0}^{2}-\theta^{2}\right)+\frac{e^{2 k(t \wedge s)}-1}{2 k} \theta^{2}\right) \\
& +e^{-k(t+s)}\left(\sigma_{0}^{2}-\theta^{2}\right)^{2}+e^{-k t}\left(\sigma_{0}^{2}-\theta^{2}\right) \theta^{2} \\
& +e^{-k s}\left(\sigma_{0}^{2}-\theta^{2}\right) \theta^{2}+\theta^{4} .
\end{aligned}
$$

Proof. See [12].

Theorem 7. One has

(a)

$$
E(V)=\frac{1-e^{-k T}}{k T}\left(\sigma_{0}^{2}-\theta^{2}\right)+\theta^{2},
$$

(b)

$$
\begin{aligned}
\operatorname{Var}(V)=\frac{\xi^{2} e^{-2 k T}}{2 k^{3} T^{2}}[ & \left(2 e^{2 k T}-4 k T e^{k T}-2\right)\left(\sigma_{0}^{2}-\theta^{2}\right) \\
& \left.+\left(2 k T e^{2 k T}-3 e^{2 k T}+4 e^{k T}-1\right) \theta^{2}\right] .
\end{aligned}
$$

Proof. (a) We obtain mean value for $V$

$$
E(V)=\frac{1}{T} \int_{0}^{T} E\left(\sigma_{t}^{2}\right) d t
$$

using Lemma 6 , and we find

$$
E(V)=\frac{1-e^{-k T}}{k T}\left(\sigma_{0}^{2}-\theta^{2}\right)+\theta^{2} .
$$

(b) Variance for $V$ equals $\operatorname{Var}(V)=E\left(V^{2}\right)-E^{2}(V)$, and the second moment may be found as follows: using formula (8) of Lemma 6: $E\left(V^{2}\right)=\left(1 / T^{2}\right) \iint_{0}^{T} E\left(\sigma_{t}^{2} \sigma_{s}^{2}\right) d t d s$,

$$
\begin{aligned}
E\left(V^{2}\right) & \\
=\frac{\xi^{2}}{T^{2}} \iint_{0}^{T}\left[e^{-k(t+s)}(\right. & \frac{e^{k(t \wedge s)}-1}{k}\left(\sigma_{0}^{2}-\theta^{2}\right) \\
& \left.\left.+\frac{e^{2 k(t \wedge s)}-1}{2 k} \theta^{2}\right)\right] d t d s
\end{aligned}
$$$$
+E^{2}(V)
$$

and taking (13) and variance formula we find

$$
\begin{array}{r}
\operatorname{Var}(V) \\
=\frac{\xi^{2}}{T^{2}} \iint_{0}^{T}\left[e ^ { - k ( t + s ) } \left(\frac{e^{k(t \wedge s)}-1}{k}\left(\sigma_{0}^{2}-\theta^{2}\right)\right.\right. \\
\left.\left.+\frac{e^{2 k(t \wedge s)}-1}{2 k} \theta^{2}\right)\right] d t d s ;
\end{array}
$$

after calculations we obtain

$$
\begin{aligned}
\operatorname{Var}(V)=\frac{\xi^{2} e^{-2 k T}}{2 k^{3} T^{2}}[ & \left(2 e^{2 k T}-4 k T e^{k T}-2\right)\left(\sigma_{0}^{2}-\theta^{2}\right) \\
& \left.+\left(2 k T e^{2 k T}-3 e^{2 k T}+4 e^{k T}-1\right) \theta^{2}\right]
\end{aligned}
$$

which achieves the proof.

Corollary 8. If $k$ is large enough, we find

$$
E(V)=\theta^{2}, \quad \operatorname{Var}(V)=0 .
$$

Proof. The idea is the limit passage $k \rightarrow \infty$.

Remark 9. In this case a swap maturity $T$ does not influence $E(V)$ and $\operatorname{Var}(V)$.

3.3. GARCH(1,1) and Volatility Swaps. GARCH model is needed for both the variance swap and the volatility swap. The model for the variance in a continuous version for Heston model is

$$
d \sigma_{t}^{2}=k\left(\theta^{2}-\sigma_{t}^{2}\right) d t+\xi \sigma_{t} d w_{2}(t) .
$$

The discrete version of the $\operatorname{GARCH}(1,1)$ process is described by Engle and Mezrich [16]:

$$
v_{n+1}=(1-\alpha-\beta) V+\alpha u_{n}^{2}+\beta v_{n},
$$

where $V$ is the long-term variance, $u_{n}$ is the drift-adjusted stock return at time $n, \alpha$ is the weight assigned to $u_{n}^{2}$, and $\beta$ is the weight assigned to $\nu_{n}$. Further we use the following relationship (19) to calculate the discrete GARCH(1,1) parameters:

$$
\begin{gathered}
V=\frac{C}{1-\alpha-\beta} \\
\theta=\frac{V}{\Delta t_{L}}, \quad \sigma_{0}=\frac{V}{\Delta t_{S}} \\
k=\frac{1-\alpha-\beta}{\Delta t} \\
\xi^{2}=\frac{\alpha^{2}(K-1)}{\Delta t},
\end{gathered}
$$

where $\Delta t_{L}=1 / 252,252$ trading days in any given year, and $\Delta t_{S}=1 / 63,63$ trading days in any given three months.

Now, we will briefly discuss the validity of the assumption that the risk-neutral process for the instantaneous variance is 
a continuous time limit of a $\operatorname{GARCH}(1,1)$ process. It is well known that this limit has the property that the increment in instantaneous variance is conditionally uncorrelated with the return of the underlying asset. This unfortunately implies that, at each maturity $T$, the implied volatility is symmetric. Hence, for assets whose options are priced consistently with a symmetric smile, these observations can be used either to initially calibrate the model or as a test of the model's validity. It is worth mentioning that it is not suitable to use atthe-money implied volatilities in general to price a seasoned volatility swap. However, our $\operatorname{GARCH}(1,1)$ approximation should still be pretty robust.

\section{Application}

In this section, we apply the analytical solutions from Section 3 to price a swap on the volatility of the CAC 40 French Index for five years (October 2009-April 2013).

The first step of this application is to study the stationarity of the series. To this end, we used the unit root test of DickeyFuller (ADF) and Philips Péron test (PP).

4.1. Unit Root Tests and Descriptive Analysis. In this section, we summarized unit root tests and descriptive analysis results of $S_{\text {cac }}$ (see Table 1).

Unit root test confirms the stationarity of the series.

In Table 2 all statistic parameters of CAC 40 French Index are shown. For the analysis 1155 observations were taken. Mean of time series is 0.0000528 , median 0 , and standard deviation 0.014589. Skewness of CAC 40 French Index is -0.078899 , so it is negative and the mean is larger than the median, and there is left-skewed distribution. Kurtosis is 7.255109, large than 3, so we called leptokurtic, indicating higher peak and fatter tails than the normal distribution. Jarque-Bera is 809.0892. So we can forecast an uptrend.

GARCH $(1,1)$ models are clearly the best performing models as they receive the lowest score on fitting metrics whilst representing the lowest MAE, RMSE, MAPE, SEE, and BIC among all models. They are closely followed by $\operatorname{GARCH}(2,1)$ which is placed comfortably lower than both $\operatorname{ARCH}(2)$ and $\operatorname{ARCH}(4)$. However the GARCH(1,1) model is simple and easy to handle. The results also show that GARCH(1,1) model improves the forecasting performance (see Table 3).

Numerical Applications. We have used Eviews software, and we found $C=2.03 \times 10^{-7}, \alpha=-0.008411, \beta=0.980310$, and $K=7.255109$. To this end, we find the following: $V=$ $72.23942208 \times 10^{-7} ; \theta=0.00182043 ; \sigma_{0}=0.0004551 ; k=$ $7.081452 ; \xi^{2}=0.11151$.

We use the relations (9) and (10) for a swap maturity $T=$ 0.9 years, and we find

$$
\begin{gathered}
E(V)=2.8273 \times 10^{-6}, \\
\operatorname{Var}(V)=5.0873 \times 10^{-9} .
\end{gathered}
$$

The convexity adjustment is $\operatorname{Var}(V) / 8 E^{3 / 2}(V)=0.13376$ and $E(\sqrt{V}) \approx-0.13208$.
TABLE 1: Unit root test.

\begin{tabular}{lcc}
\hline Test & ADF & PP \\
\hline$S_{\text {cac }}$ & -34.16458 & -35.01017 \\
\hline
\end{tabular}

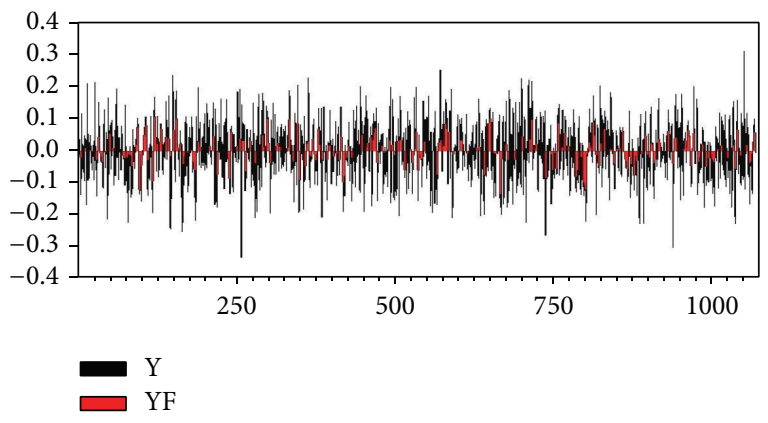

FIgURE 1: GARCH(1,1) CAC 40 French Index forecasting.

Remark 10. If the nonadjusted strike is equal to 0.23456 , then the adjusted strike is equal to $0.23456-0.13376=0.1008$.

According to Figure $3 E(V)$ is increasing exponentially and converges when $T \rightarrow \infty$ towards $3.3140 \times 10^{-6}$. But $\operatorname{Var}(V)$ is increasing linearly during the first year and is decreasing exponentially during $[1, \infty$ [ years when $\operatorname{Var}(V) \rightarrow 0$, if $T \rightarrow \infty$.

4.2. Conclusions. According to results founded, the GARCH(1,1) is a very good model for modeling the volatility swaps for stock market. Also, we remark the influence of the French financial crisis (2009) on CAC 40 French Index.

Moreover, we presented a probabilistic approach, based on changing of time method, to study variance and volatility swaps for stock market with underlying asset and variance that follow the Heston model. We obtained the formulas for variance and volatility swaps but with another structure and another application to those in the papers by Brockhaus and Long [10] and Swishchuk [12]. As an application of our analytical solutions, we provided a numerical example using CAC 40 French Index to price swap on the volatility (Figure 1).

Also, we compared the forecasting performance of several GARCH models using different distributions for CAC 40 French Index. We found that the $\operatorname{GARCH}(1,1)$ skewed Student $t$ model is the most promising for characterizing the dynamic behaviour of these returns as it reflects their underlying process in terms of serial correlation, asymmetric volatility clustering, and leptokurtic innovation. The results also show that $\operatorname{GARCH}(1,1)$ model improves the forecasting performance. This result later further implies that the GARCH(1,1) model might be more useful than the other three models $(\mathrm{ARCH}(2), \mathrm{ARCH}(4)$, and $\operatorname{GARCH}(2,1))$ when implementing risk management strategies for CAC 40 French Index (Figure 2). 
TABLE 2

\begin{tabular}{ccccccc}
\hline & Mean & Median & Std. Dev. & Skewness & Kurtosis & Jarque-B \\
\hline$S_{\text {cac }}$ & $5.28 E-5$ & 0.0000 & 0.014589 & -0.078899 & 7.255109 & 809.0892 \\
\hline
\end{tabular}

TABLE 3

\begin{tabular}{|c|c|c|c|c|c|c|}
\hline Models & Adju $R^{2}$ & SEE & $\mathrm{BIC}$ & RMSE & MAE & MAPE \\
\hline $\mathrm{ARCH}(2)$ & 0.989953 & 0.007369 & -2.620676 & 0.013674 & 0.009786 & 3.612218 \\
\hline $\mathrm{ARCH}(4)$ & 0.989971 & 0.007062 & -2.801014 & 0.010689 & 0.007441 & 3.469134 \\
\hline $\operatorname{GARCH}(2,1)$ & 0.992352 & 0.003072 & -7.893673 & 0.002668 & 0.002835 & 2.946543 \\
\hline GARCH $(1,1)$ & 0.999122 & 0.002672 & -8.993776 & 0.002668 & 0.001983 & 2.743416 \\
\hline
\end{tabular}

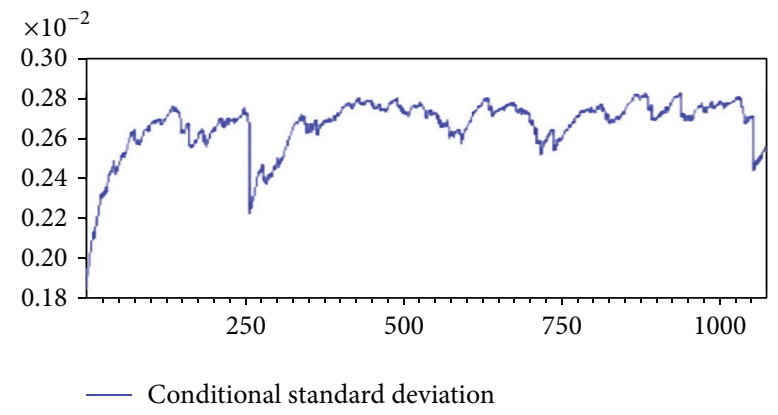

FIgURE 2: CAC 40 French Index conditional variance.

\section{Appendix}

We give a reminder for each parameter.

(1) Std. Dev. (standard deviation) is a measure of dispersion or spread in the series. The standard deviation is given by

$$
s=\sqrt{\frac{1}{N-1} \sum_{i=1}^{N}\left(y_{i}-\bar{y}\right)^{2}}
$$

where $N$ is the number of observations in the current sample and $\bar{y}$ is the mean of the series.

(2) Skewness is a measure of asymmetry of the distribution of the series around its mean. Skewness is computed as

$$
S=\frac{1}{N} \sum_{i=1}^{N}\left(\frac{y_{i}-\bar{y}}{\widehat{\sigma}}\right)^{3}
$$

where $\widehat{\sigma}$ is an estimator for the standard deviation that is based on the biased estimator for the variance $(\widehat{\sigma}=$ $s \sqrt{(N-1) / N})$.

(3) Kurtosis measures the peakedness or flatness of the distribution of the series. Kurtosis is computed as

$$
K=\frac{1}{N} \sum_{i=1}^{N}\left(\frac{y_{i}-\bar{y}}{\widehat{\sigma}}\right)^{4}
$$

where $\widehat{\sigma}$ is again based on the biased estimator for the variance.

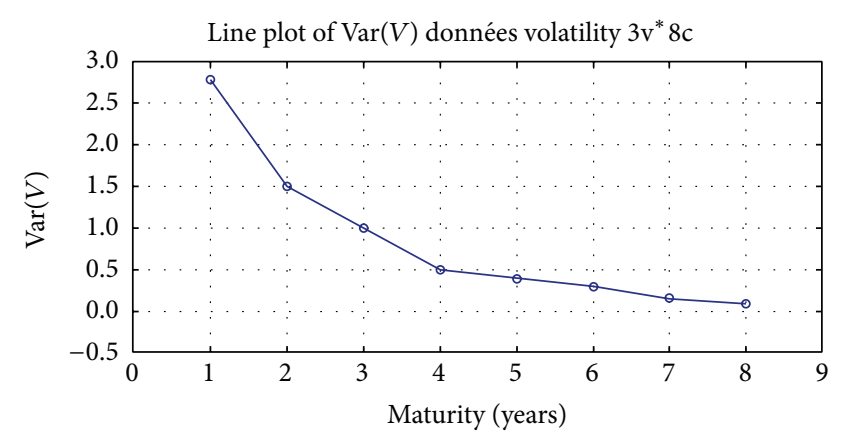

(a)

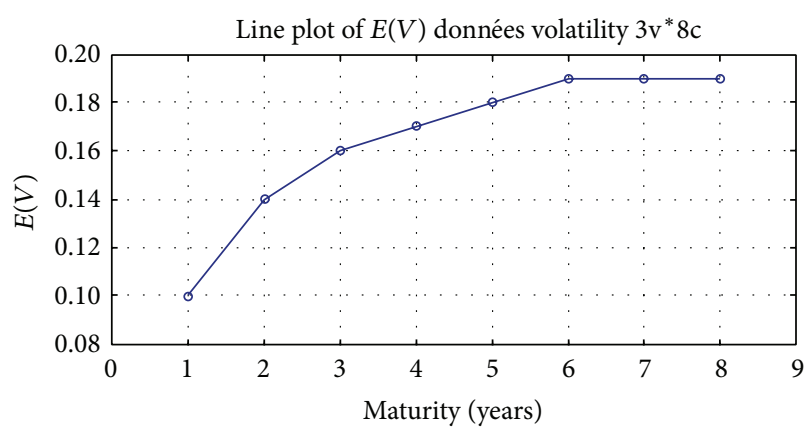

(b)

Figure 3: CAC 40 French Index $E(V)$ and $\operatorname{Var}(V)$.

(4) Jarque-Bera is a test statistic for testing whether the series is normally distributed. The statistic is computed as

$$
\text { Jarque-Bera }=\frac{N}{6}\left(S^{2}+\frac{(K-3)^{2}}{4}\right),
$$

where $S$ is the skewness and $K$ is the kurtosis.

(5) Mean absolute error (MAE) is as follows: MAE = $(1 / N) \sum_{i=1}^{N}\left|y_{i}-\widehat{y}_{i}\right|$.

(6) Mean absolute percentage error (MAPE) is as follows: MAPE $=\sum_{i=1}^{N}\left|\left(y_{i}-\widehat{y}_{i}\right) / y_{i}\right|$.

(7) Root mean squared error (RMSE) is as follows: $\operatorname{RMSE}=\sqrt{(1 / N) \sum_{i=1}^{N}\left(y_{i}-\widehat{y}_{i}\right)^{2}}$.

(8) Adjusted R-squared (adjust $R^{2}$ ) is considered.

(9) Sum error of regression (SEE) is considered. 
(10) Schwartz criterion (BIC) is measured by $n \ln (\mathrm{SEE})+$ $k \ln (n)$.

\section{Conflict of Interests}

The authors declare that there is no conflict of interests regarding the publication of this paper.

\section{Acknowledgment}

This work was given ATRST (ex: ANDRU) financing within the framework of the PNR Project (Number 8/u23/1050) and Averroès Program.

\section{References}

[1] F. Black and M. Scholes, "The pricing of option and corporate liabilities," Journal of Political Economy, vol. 81, no. 3, pp. 637659, 1973.

[2] J. Hull, Options, Futures and Other Derivatives, Prentice Hall, New York, NY, USA, 4th edition, 2000.

[3] M. Broadie and A. Jain, "The effect of jumps and discrete sampling on volatility and variance swaps," International Journal of Theoretical and Applied Finance, vol. 11, no. 8, pp. 761-797, 2008.

[4] H. Baili, "Stochastic analysis and particle filtering of the volatility," IAENG International Journal of Applied Mathematics, vol. 41, no. 1, article 09, 2011.

[5] L. Cao and Z.-F. Guo, "Optimal variance swaps investments," IAENG International Journal of Applied Mathematics, vol. 41, no. 4, pp. 334-338, 2011.

[6] S. Heston, "A closed-form solution for options with stochastic volatility with applications to bond and currency options," Review of Financial Studies, vol. 6, pp. 327-343, 1993.

[7] J. C. Cox, J. Ingersoll, and S. Ross, "A theory of the term structure of interest rates," Econometrica. Journal of the Econometric Society, vol. 53, no. 2, pp. 385-407, 1985.

[8] T. Bruce, Fixed Income Securities: Tools for Today's Markets, John Wiley \& Sons, New York, NY, USA, 1996.

[9] K. Demeterfi, E. Derman, M. Kamal, and J. Zou, "A guide to volatility and variance swaps," The Journal of Derivatives, vol. 6, no. 4, pp. 9-32, 1999.

[10] O. Brockhaus and D. Long, "Volatility swaps made simple," Risk Magazine, vol. 2, no. 1, pp. 92-96, 2000.

[11] A. Javaheri, The volatility process [Ph.D. thesis], Ecole des Mines de Paris, Paris, France, 2004.

[12] A. Swishchuk, "Variance and volatility swaps in energy markets," Journal of Energy Markets, vol. 6, no. 1, pp. 33-49, 2013.

[13] R. He and Y. Wang, "Price pseudo-variance, pseudo covariance, pseudo-volatility, and pseudo-correlation swaps-in analytical close forms," in Proceedings of the 6th PIMS Industrial Problems Solving Workshop (PIMS IPSW '02), pp. 27-37, University of British Columbia, Vancouver, Canada, 2002.

[14] A. Swishchuk and A. Kalemanova, "The stochastic stability of interest rates with jump changes," Theory Probability and Mathematical Statistics, vol. 61, pp. 161-172, 2000.

[15] B. Oksendal, Stochastic Differential Equations: An Introduction with Applications, Springer, New York, NY, USA, 1998.

[16] R. F. Engle and J. Mezrich, "Grappling with GARCH," Risk Magazine, vol. 8, no. 9, pp. 112-117, 1995. 


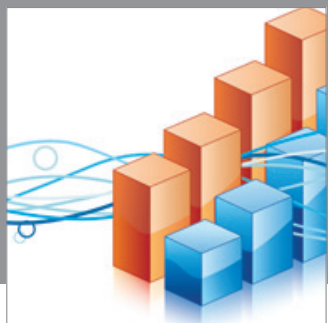

Advances in

Operations Research

mansans

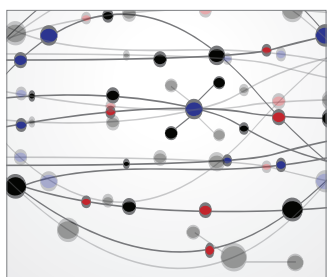

The Scientific World Journal
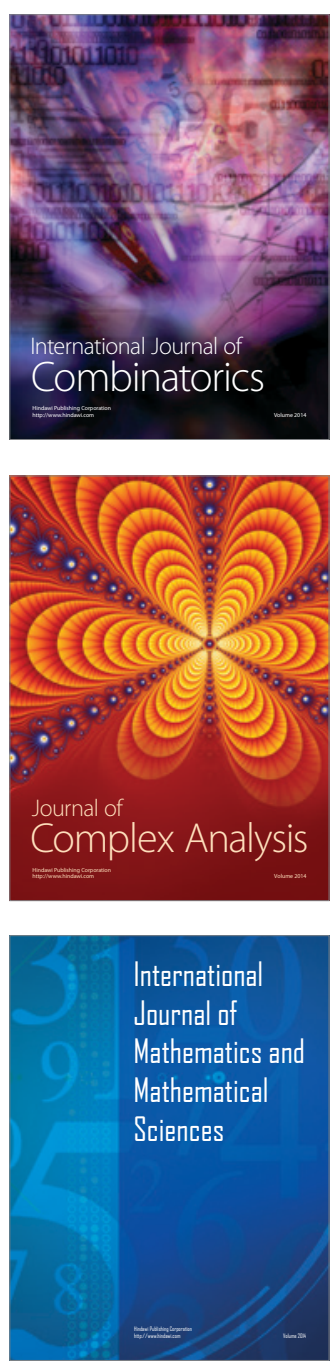
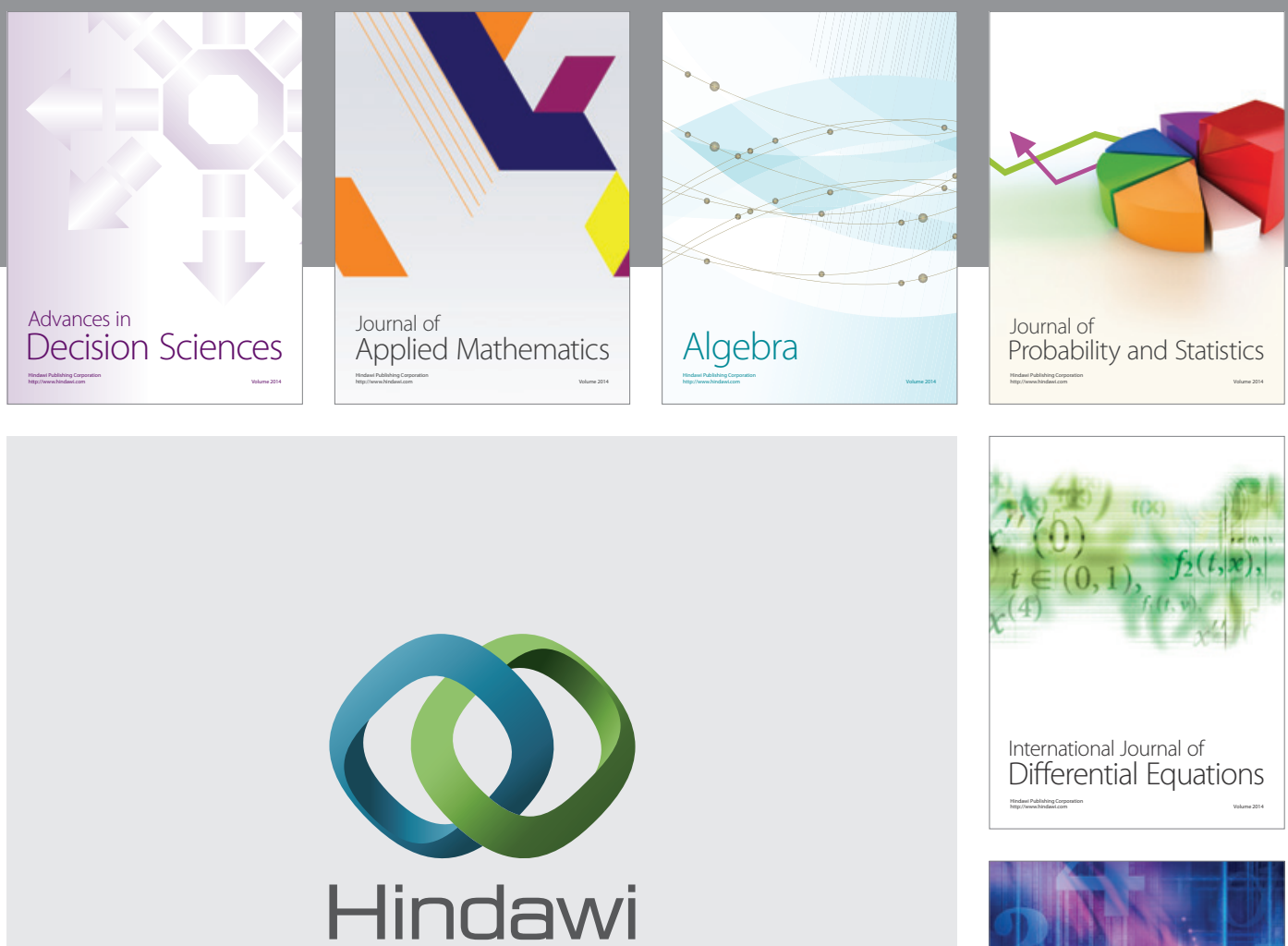

Submit your manuscripts at http://www.hindawi.com
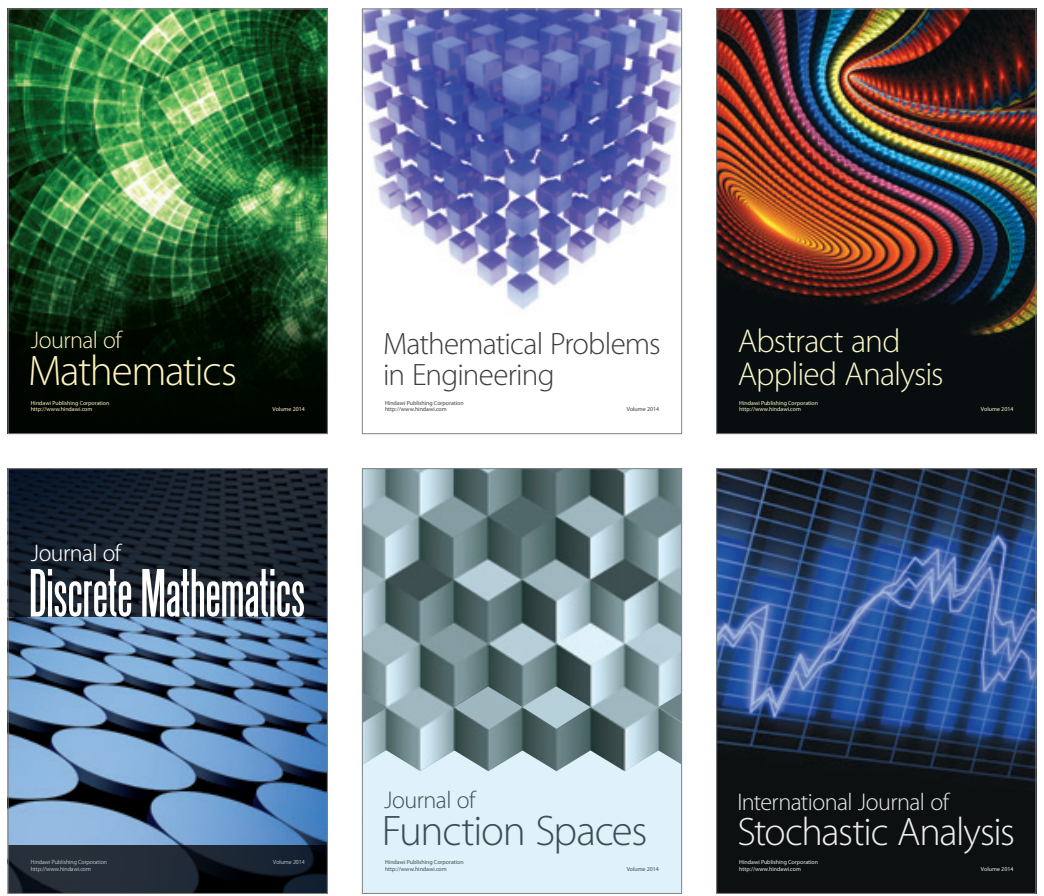

Journal of

Function Spaces

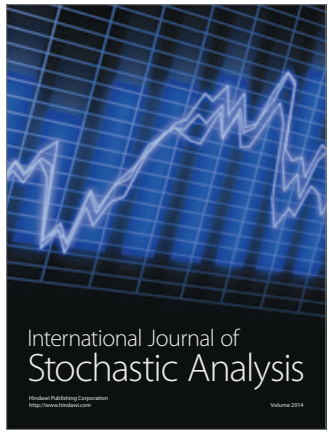

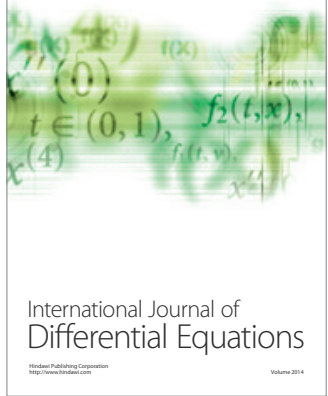
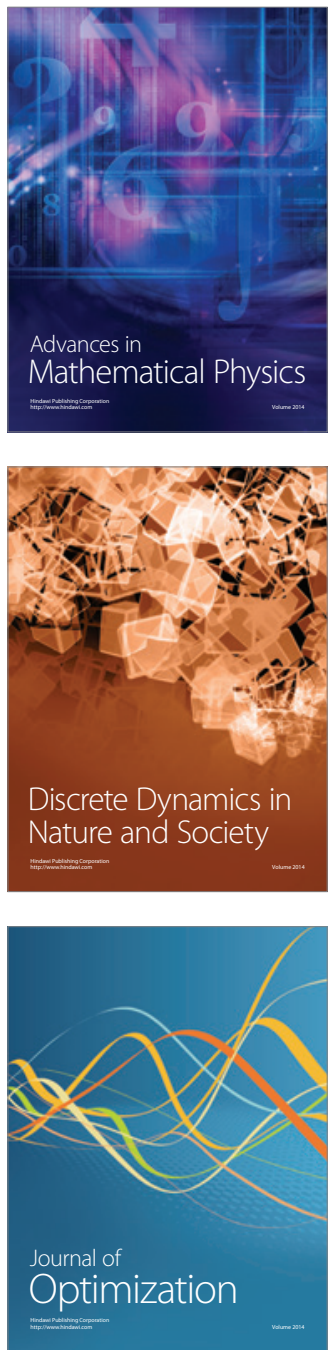